\title{
Research on the Development Path of Culture and Tourism Integration in Zigong Section of Tuojiang River Basin
}

\author{
Ping Zhao \\ Yinxing Hospitality Management College of CUIT, Chengdu, Sichuan 611743, China \\ zhaoping@yxhmc.edu.cn
}

\begin{abstract}
Tuojiang River is a main tributary of the Yangtze River and a well-known water system in Sichuan. Zigong section of Tuojiang River Basin is an important part of social and economic development in Zigong, as well as a considerable node of Chengdu-Chongqing twin cities economic circle and Bashu cultural and tourism corridor. The integration of culture and tourism is of great strategic significance for improving the market influence, attractiveness, and competitiveness of the tourism industry in Zigong section of Tuojiang River Basin. Based on the systematic analysis of the development status, industrial chain and consumption conversion rate of tourism resources, this paper puts forward the specific path of the integration of culture and tourism. The purpose is to help Zigong City integrate into the Yangtze River economic belt and free trade zone, connect Chengdu-Chongqing twin cities economic circle, and finally become a characteristic tourist destination in Bashu cultural and tourism corridor.
\end{abstract}

Keywords: Integration, culture and Tourism, development path, Zigong section, Tuojiang

\section{INTRODUCTION}

The concept and operation of integration of culture and tourism has become a national strategic thinking. The theme of China Tourism Day 2019 is "culture and tourism integration, a better life". It has become an urgent need for the development of tourism industry to further promote the integration of culture and tourism and lead high-quality tourism with culture. Besides, the integration of culture and tourism is a new growth point and driving force for regional economic and social development. Tuojiang River is one of the main rivers in the hinterland of Sichuan Province. It is an important channel connecting the middle and lower reaches of the Yangtze River. Zigong section of Tuojiang River Basin has been listed as the core area of integrated industrial development of Neijiang and Zigong, which is an important part of social and economic development in Zigong, as well as a considerable node of Chengdu-Chongqing twin cities economic circle and Bashu cultural and tourism corridor. Zigong section of Tuojiang River Basin is about $110.15 \mathrm{~km}$ long, mainly involving 20 towns and townships flowing through the main stream of Tuojiang River, with an area of about $983.75 \mathrm{~km}^{2}$. Based on the study of characteristics of resources and spatial environment in Zigong section of Tuojiang River Basin, this paper tries to construct the integrated development path of culture and tourism, to promote the high-quality development of Zigong's tourism industry, and help the section to become a characteristic tourist destination in Bashu culture and tourism corridor.

\section{LITERATURE REVIEW}

Western scholars' research on the integration of culture and tourism can be divided into macro and micro levels. At the macro level, the research mainly focuses on the analysis of the reasons, driving factors, feasibility and so on. The case studies mainly focus on the relationship between cultural industry and tourism development mode. The selected cases are Cross River State of Nigeria (Ogaboh Agba, Ikoh, et al, 2010) [1], Botswana (Saarinen, Moswete and Monare, 2014) [2], Lithuania (Jureniene, 2011) [3], Southern Spain (Ballesteros and Ramirez, 2006) [4], et al. For the driving factors of the integration of culture and tourism, scholars believe that there are mainly multi-level and high-quality demands of consumers for tourism products, as well as the tourism attributes of historical and cultural resources themselves (Apostolakis, 2003)[5]. At the micro level, the research mainly focuses on the opportunity (Yu and Yen, 2012; Ling and Alan, 2012)[6-7], specific ways and approaches (Juzefovic, 2015) of the integration of culture and Tourism[8].

The research on Zigong section of Tuojiang River Basin in domestic academic mainly focuses on the field of water ecological environment protection (Yang and Zhan, 1995)[9]. There are some research on the integration of culture and tourism, which usually put forward the development and utilization of cultural resources to achieve the development of tourism from the perspective of government management (He and Yang, 2016; Wang, 2018)[10-11]. In the study of Zigong tourism development, some studies have involved in the integration of culture and tourism of ancient towns along the Tuojiang River in 
Zigong, mainly in the following two aspects. One is to carry out tourism image positioning and tourism product development around Zigong's tourism resources of salt, dragon and lamp (Lai and Yang, 2009; Li and Liang, 2011)[12-13]. The other is the study of tourism development strategy for tourism enterprises (Wang, 2014; Zou and Wang, 2015)[14-15].

In conclusion, the research on the integration of culture and tourism in Zigong section of Tuojiang River Basin is still blank. The relevant research focus on the development of tourism resources and the design of tourism products, lacking of in-depth study of cultural connotation and close relationship between culture and tourism. Therefore, it is not able to build a system of integrated development of culture and tourism, and effectively solve the problem of separation of culture and tourism. From the development of tourism resources to the upgrading of culture and tourism consumption, this paper regards culture and tourism industry as the formation of a new industry from the perspective of industrial integration. This paper intends to build a normalized integrated development path of culture and tourism to realize the value of new industry of culture and tourism. By extending the culture and tourism industry chain, the rich cultural heritage and high tourism value of Zigong section of Tuojiang River Basin can be explored.

\section{CULTURE AND TOURISM RESOURCES IN ZIGONG SECTION OF TUOJIANG RIVER BASIN}

A comprehensive analysis of the state of tourism resources and spatial environment is the basic work to determine the development direction of cultural tourism integration in the Zigong section of Tuojiang River Basin. The section is the lower reaches of the Tuojiang River and involves Da'an District, Yantan District and Fushun County. Zigong is a famous historical and cultural city and an excellent tourist city in China. It is located in the middle of Chengdu-Chongqing twin cities economic circle and the geometric center of southern Sichuan urban agglomeration. The Zigong section of Tuojiang River Basin has better resources and space conditions for the development of leisure tourism.

\subsection{Spatial Environment of Culture and Tourism Resources}

Zigong section of Tuojiang River Basin is high in the northwest and low in the southwest. Tuojiang River runs through this area from north to south. The landform is mainly hills with an average altitude of about $260-400 \mathrm{~m}$. Starting from the inflow of Miaoba Town and outflow to Changtan Town, the Tuojiang River turns into the southeast flow into Luzhou City since the Fuxi River merges into Tuojiang in Fushun County. The forest coverage is more than $35 \%$. There are lots of rural gardens, woodland, orchard and farmland all over the area. The ancient towns along Tuojiang River are linear and densely distributed. The section is a V-Class river course with outstanding water energy resources, which is navigable to 300 ton ships. At present, there are two navigation power stations and multiple wharves. The waterway upgrading project of Zigong section of Tuojiang has been constructed since January, 2020. It is planned to renovate 103.9 kilometers of waterway, with a total investment of about 7.8 billion yuan. The waterway will bear a shipping capacity of 1000 tons in the future. Therefore, Zigong section of Tuojiang River Basin can rely on the advantages of spatial environment, integrate cultural and tourism resources along the river, and develop a number of featured tourism products.

\subsection{Current Situation of Culture and Tourism Resources}

The culture and tourism resources of Zigong section of Tuojiang River Basin are scattered along the whole waterway and tributary areas within the flow range of hundreds of kilometers of Tuojiang River. At present, the developed tourism resources include Gexian Mountain, Niufo ancient town, Shishi ancient town, Zhaohua ancient town, Miaoxian Lake, the hometown of Liu Guangdi, Fushun West Lake and Confucious' temple, Qingshanling Forest Park, etc. Among them, the ancient towns have the most development potential value, which are also the main support for the integrated development of culture and tourism in Zigong section of Tuojiang River Basin. Niufo ancient town is located in the middle and upper reaches of Tuojiang River, which is an important town and ferry in the north of Zigong section of Tuojiang River Basin. The town was built in the period of Emperor $\mathrm{Wu}$ of the Northern Zhou Dynasty, with a history of more than 1000 years. In the early Qing Dynasty, it had a grand occasion of nine streets and eighteen lanes. Lcated on the East Bank of Tuojiang River, Shishi ancient town was built in the Song Dynasty. It was the only important wharf for Zigong to sell salt in the Qing Dynasty. It was rated as a provincial famous historical and cultural town in 2009. Zhaohua ancient town is not only prosperous because of salt, but also famous for the only production and sales of silk in the ancient towns along the river, and enjoys the reputation of "the transportation hub on the ancient salt road". The town is close to mountains and rivers, about $70 \%$ of which are historical buildings of Ming and Qing Dynasties. It was rated as a national famous historical and cultural town in 2010 .

\section{PROBLEMS AND OPPORTUNITIES OF THE INTEGRATION OF CULTURE AND TOURISM}

From north to south, Zigong section of Tuojiang River Basin is distributed with Miaoba, Niufo, Shishi, Zhaohua 
ancient town, etc. The cultural and tourism resources are endowed well, but there are still problems such as insufficient resource development and integration, low consumption conversion rate, low industrialization level, and the pattern of cultural and tourism integration development has not yet been formed.

\subsection{The Main Problems}

\subsubsection{Insufficient resource development and integration}

The tourism resources of Zigong section of Tuojiang River Basin are scattered along the whole waterway and tributary areas within the flow range of hundreds of kilometers. The tourism resources are scattered, which leads to the failure of centralized and continuous development of tourism products and poor efficiency of tourism project agglomeration. In addition, due to the limitation of basin topography, there is a lack of effective tourism routes in series, and different types of resources are not complementary. The vast majority of tourism resources are still in the initial development state. Because of the lack of effective and reasonable development and utilization of resources, the tourism product system is unreasonable, and the economic income is poor. The construction of scenic spots is insufficient, and tourism carriers are lacking. Except the dinosaur Lantern Festival, Zigong has no scenic spot with more than 1 million visitors.

\subsection{2. low consumption conversion rate}

Limited by the economic development, Zigong section of Tuojiang River Basin is lack of tourism supporting infrastructure, which leads to the incomplete service and consumption system of tourism projects, so it is difficult for tourists to take this as a tourist destination and stay overnight. The tourism projects focuses on sightseeing, lacking in-depth experience and entertainment format, resulting in short stay time and low overall consumption conversion rate. Due to the historical development of the administrative region, traffic location and other factors, tourists mainly come from Zigong, Neijiang and Luzhou, but not enough from other cities and regions. The source market is still fixed and single.

\subsection{3. low degree of tourism industrialization}

There are many ancient towns in Zigong section of Tuojiang River Basin, with high cultural taste and good resource endowment, but the degree of tourism industrialization is low. There is no perfect tourism industry chain to drive the economic development of the whole region. The development of core resources is insufficient, the attraction of products is not enough, so the degree of tourism industrialization is not high. The overall development speed of Zigong's tourism industry has declined in recent years. The number of tourists received has only increased by $2.4 \%$ over the previous year, and the growth rate of Zigong's tourism industry is behind that of the whole province in 2019. Zigong's ranking in the whole province and the south of Sichuan is also declining. The number of domestic tourists received has dropped from the fifth in 2000 to the thirteenth now, and the tourism income has dropped from the fifth to the twelfth. The share of domestic tourists received by Zigong in southern Sichuan has decreased from $27.23 \%$ in 2000 to $21.28 \%$ now, and the tourism income has decreased from $28.20 \%$ to $20.58 \%$, which is $5.24 \%$ and $3.92 \%$ lower than the average speed of southern Sichuan.

Table 1 Tourism economy of Sichuan, Chongqing and southern Sichuan in 2018 and 2019

\begin{tabular}{|c|c|c|c|c|c|c|c|c|}
\hline \multirow{2}{*}{ Subject } & \multicolumn{4}{|c|}{2018} & \multicolumn{4}{c|}{2019} \\
\cline { 2 - 9 } & $\begin{array}{c}\text { Number } \\
\text { of } \\
\text { tourists }\end{array}$ & $\begin{array}{c}\text { Growth } \\
\text { rate (\%) }\end{array}$ & $\begin{array}{c}\text { Tourism } \\
\text { revenue }\end{array}$ & $\begin{array}{c}\text { Growth } \\
\text { rate (\%) }\end{array}$ & $\begin{array}{c}\text { Number } \\
\text { of } \\
\text { tourists }\end{array}$ & $\begin{array}{c}\text { Growth } \\
\text { rate (\%) }\end{array}$ & $\begin{array}{c}\text { Tourism } \\
\text { revenue }\end{array}$ & $\begin{array}{c}\text { Growth } \\
\text { rate (\%) }\end{array}$ \\
\hline Sichuan & 70200 & 4.9 & 10112.75 & 13.3 & 75100 & 6.98 & 11594.32 & 15.80 \\
\hline $\begin{array}{c}\text { Chongqin } \\
\text { g }\end{array}$ & 59300 & 10.1 & 4344.15 & 31.3 & 65700 & 10 & 5734 & 32 \\
\hline Chengdu & 24300 & 15.8 & 3712.6 & 22.4 & 28000 & 15.2 & 4663.5 & 25.6 \\
\hline Zigong & 4620.41 & 14.78 & 391.72 & 14.89 & 4730 & 2.4 & 440.09 & 12.35 \\
\hline Yibin & 6535.1 & 25.23 & 687.28 & 27.58 & 7400 & 13 & 820 & 19 \\
\hline Luzhou & 5198.61 & 5.34 & 512.8 & 16.1 & 5450 & 4.83 & 590 & 15.05 \\
\hline
\end{tabular}




\begin{tabular}{|l|l|l|l|l|l|l|l|l|}
\hline Nejiang & 4290.58 & 10 & 311.7 & 18.1 & 4642.35 & 8.29 & 363.2 & 16.52 \\
\hline
\end{tabular}

(unit: 10000 person times, 100 million yuan) upgrading. On the basis of fully considering the future tourism market demand, we should integrate the resources

\subsection{Development Opportunities}

Zigong is known as the millennium salt capital, hometown of dinosaurs and southern Lamp city. Tourism resources represented by human landscapes are mainly concentrated in the central and western regions, but less in the east of Zigong City where Tuojiang River flows. The eastern region of Zigong along the Tuojiang river is a place that has not been fully valued and developed. However, as a tributary of the Yangtze river, Sichuan well-known water system and water transport channel, the value of Tuojiang River cannot be ignored. After the implementation of channel expansion strategies, the benefits brought by the traffic volume of Tuojiang will give the section a considerable development opportunity. In particular, the proposal of the national strategy of Chengdu-Chongqing twin cities economic circle has an important milestone significance for Zigong development, and provides new opportunities for accelerating the development of Zigong tourism industry. As the gateway of Zigong waterway, the development and utilization of tourism resources along Tuojiang River will become an important part of Zigong's economic development.

\section{INTEGRATED DEVELOPMENT PATH OF CULTURE AND TOURISM}

The implementation of "tourism plus" measures can promote the industrial integration, form the tourism industry ecological community in the Zigong section of Tuojiang River Basin, and promote the development of regional economy. We should promote "tourism plus" to lead the innovation of business forms, achieve new breakthroughs in the integration of tourism industry. Specifically speaking, it is to promote the upgrading of tourism industry by industrial integration, expand the new space for the development of tourism industry, cultivate new hot spots of tourism consumption, and promote social progress and ecological civilization construction in the Zigong section of Tuojiang River Basin.

\subsection{Spatial Pattern: Cultural Tourism Consumption Upgrading}

Tourism is the carrier of culture and culture is the soul of tourism[16]. If Zigong section of Tuojiang River Basin wants to promote the deep integration development of culture and tourism, it is necessary to fully integrate local resources and give tourism industry more profound cultural connotation. In particular, the characteristics of resources, culture and environment should be highlighted to form a spatial pattern of cultural tourism consumption and cultural advantages of the ancient towns along the river, and determine the spatial structure and product system of the development of culture and tourism industry.

\subsubsection{Da'an section: ancient section of water commerce and culture}

This section is the shipping combination section of Zigong well salt and other materials trade out of Sichuan. It has rich historical relics in several ancient towns such as Miaoba, Yongjia, Niufo, Huilong and Washi in Da'an District. Therefore, it is feasible to focus on the development of heritage tourism, cultural experience, rural leisure, mountain recreation and other tourism products with the ancient commerce culture as the context and cultural experience as the development thinking.

\subsubsection{Fushun section: waterfront leisure and health care section}

This section is the downstream area of Zigong section of Tuojiang River Basin. The water flow is gentle, forming wetland, lake and other landscapes along the way, mainly involving Fushun County and Yantan District. In the plan, the ecological landscape will be built to create the largest open park of water amusement. Based on Qingshanling Forest Park, Zhaohua ancient town and other resources, we can reasonably guide the development of rural tourism along the river, and jointly build a brand of leisure and healthy tourism.

\subsection{Spatial Production: Salt Culture Experience in Ancient Towns}

With the growing tourism market for personalized demand, the simple sightseeing tourism of ancient towns is not enough to constitute the inevitable cause of tourists. Zigong has a long history of salt industry, so it is a feasible way to build salt culture experience tourism products in ancient towns. The construction of Bashu cultural and tourism corridor has brought great opportunities for Zigong salt culture protection, inheritance and tourism development. Therefore, the space production of salt culture and tourism of ancient towns in Tuojiang River Basin can be constructed. Through the production of culture and tourism space including physical space, experiential space and landscape symbol space, Zigong section of Tuojiang River Basin is provided with more salt cultural tourism space that can be read, participated and consumed. 


\subsubsection{Physical space}

There are many towns set up because of salt along the Tuojiang River, such as Niufo, Xianshi and Shishi ancient town. Taking the ancient town as the space carrier to build salt merchants' cultural experience venues, adopting cultural and creative ideas and integrating high-tech means, the salt transportation culture of Tuojiang can be connected with education, traditional Chinese medicine, health care and other industries. Three series of tourism products are planned and developed. The first is to integrate well salt cultural resources, salt trading, salt transportation and other traditional skills and culture, and develop research and learning tourism products. The second is to develop immersive cultural tourism products based on the heritage culture of the ancestral hall of salt merchants and the well salt themed folk street. The third is to follow the current development trend of health tourism and develop health tourism products such as salt therapy and health preservation.

\subsubsection{Experiential space}

Zigong's well salt production began in the Zhangdi period of the Eastern Jin Dynasty (76-88), with a history of more than 2000 years. It was well-known throughout Sichuan in the Tang and Song Dynasties and further developed in the Ming and Qing Dynasties. After the middle of the Qing Dynasty, Zigong became the center of salt industry in Sichuan. Nowadays, Zigong is still the largest well salt production base in China known as the well salt capital. Therefore, businesses such as food themed catering, featured shopping spots and accommodation can be introduced into the characteristic block of the ancient towns to form a space for participating in cultural tourism, such as the living experience hall of salt business culture, salt business food yard, salt business inn, salt business accommodation, etc. In the riverside area, activities such as Tuojiang water sightseeing, dragon boat racing and wharf worship can be built around the wharf site.

\subsubsection{Landscape symbol space}

Both sides of the Tuojiang River have beautiful natural scenery through the ancient towns, which have rich cultural resources and cultural heritage of the traditional wharf. For example, Niufo ancient town is prosperous relying on Tuojiang commerce and transportation, which is known as Tuojiang commerce port and logistics center of Ming and Qing Dynasties. Therefore, it attracts merchants from Sichuan, Hubei, Guangdong, Jiangxi, Fujian and other provinces to gather here and build a magnificent architectural landscape of Eight Temples of Five Provinces. Supported by the salt transportation culture of Tuojiang, the space of landscape symbol with the salt transportation street of the ancient towns as the core will be constructed. The salt transportation culture will be integrated into the historical block construction, wharf restoration and reconstruction of the ancient towns, so as to create a salt transportation cultural landscape with both visual effect and artistic charm, and enhance the salt culture atmosphere of the ancient towns. We should encourage ancient towns to create logos with regional cultural characteristics, and show their cultural heritage and innovation. A series of salt transport cultural and creative products are designed and developed through visualization, subjectivity and productization to form a unique cultural memory and symbol.

\subsection{Measures to Promote Integrated Development}

The integrated development of culture and tourism is to integrate and restructure the cultural tourism industry and related elements, break through the original element field and form a new business form. The development of tourism industry in the Zigong section of Tuojiang River Basin should be based on the main cultural landscapes along both sides of the Tuojiang River. The water area, wetland, forest belt, rural area, historical culture and folk customs and other related scenic spots and industries along the Tuojiang can be connected in series to create the tourism products of cultural leisure including ecological garden, hydrophilic leisure, folk customs, historical culture, health vacation and natural landscape. It is necessary for the government to formulate comprehensive measures to achieve the above goals, mainly including the following three actions. Firstly, we should fully understand the important role and position of the integration of culture and tourism, establish a leading group for tourism development and construction in the Zigong section of Tuojiang River Basin, regularly hold joint meetings for tourism development, coordinate and allocate resources along the line, and promote coordination and cooperation among different departments, regions and industries. Secondly, the management mechanism of culture and tourism integration in the Zigong section of Tuojiang River Basin should be improved. It is necessary to establish a three-level management participation system of government, industry and enterprise, and do a good job in the development and construction of tourism industry, publicity and promotion, market development and other related work. Thirdly, we can innovate and expand the investment and financing mechanism, guide the financial sector to increase its support for cultural and tourism enterprises. Through the development of new financial products, we will increase support in terms of loan cycle, line of credit, discount interest, etc., and further expand the development space of the culture and tourism market.

\section{Conclusion}

The culture and tourism resources in Zigong section of Tuojiang River Basin are endowed well, but there are still 
some problems such as insufficient resource development and integration, low consumption conversion rate and low industrialization degree. It is urgent to improve the quality and efficiency of cultural tourism development in Zigong section of Tuojiang River Basin through the allocation of cultural and tourism industry elements and the integration of business forms. The main measures are as follows. First of all, the tourism characteristics of Zigong section of Tuojiang River Basin are condensed, by integrating the tourism resources and cultural advantages of the ancient towns along the river, the spatial pattern of cultural tourism consumption upgrading is formed. Secondly, we should seize the development opportunity brought by the construction of Bashu cultural and tourism corridor for Zigong salt culture protection and tourism development, and realize the development goal of international cultural tourism destination through the spatial production of salt culture tourism in the ancient towns of Tuojiang River Basin. Finally, the government guarantees the integrated development of culture and tourism in Zigong section of Tuojiang River Basin through mechanism and system innovation measures.

\section{ACKNOWLEDGMENT}

This work was supported by Tuojiang River Basin High-quality Development Research Center of Sichuan key research base of social sciences (TJGZL2019-06), the National Social Science Fund of China (19BJY210), and Sichuan Revolutionary Old Area Development Research Center (SLQ2018B-11).

\section{REFERENCES}

[1] A. M. Ogaboh Agba, M. U. Ikoh, A. O. Bassey, et al. Tourism industry impact on Efik's culture, Nigeria. International Journal of Culture Tourism \& Hospitality Research, 4(4) (2010) 355-365.

[2] J. Saarinen, N. Moswete, M. J. Monare. Cultural tourism: new opportunities for diversifying the tourism industry in Botswana. Bulletin of Geography Socio Economic, 26(26) (2014) 7-18.

[3] V. Jureniene. Interaction between Cultural Heritage and Industries of Cultural Tourism in Lithuania. Transformations in Business\& Economics, (10) (2011) 647-663.

[4] E. R. Ballesteros, M. H. Ramirez. Identity and community-Reflections on the development of mining heritage tourism in Southern Spain. Tourism Management, 28 (2006) 667-687.
[5] A. Apostolakis. The Convergence Process in Heritage Tourism. Annals of Tourism Research, (30) (2003) 795-812.

[6] A. H. C. Yu, I. Y. Yen. Segmenting Art Festival Visitors by Motivations. Annals of the Alexandru Ioan Cuza University Economics,59(1) (2012) 213-226.

[7] M. Ling, A. L. Alan. Historical and geographical context in festival tourism development, Journal of Heritage Tourism, 7(1) (2012) 13-31.

[8] A. Juzefovic. Creative Tourism: the Issues of Philosophy, Sociology and Communication. Creativity Studies, (8) (2015) 73-74.

[9] C. Yang, Y. Zhan. Water environment and economic development of Zigong City. Sichuan Environment, (002) (1995) 7.

[10] Z. He, G. Yang, et al. Investigation and reflection on the integration and interactive development of modern agricultural industry in Yantan District, Zigong City. Sichuan Agricultural Science and technology, (6) (2016) 59-61.

[11] M. Wang. Highlighting quality and accelerating the integrated development of Zigong culture and tourism. Zigong Daily, 2018(2)-9-14.

[12] B. Lai, L. Yang. Research on market value mining and in-depth development of salt culture themed tourism products -- a case study of the dead sea of Great Britain and Zigong Salt City. Human Geography, (2) (2009) 56-59.

[13] G. Li, Y. Liang. Problems in Zigong's tourism product development and countermeasures. Guide to becoming rich in science and technology, (9) (2011) 17.

[14] Z. Wang. SWOT analysis of Zigong tourism development. Journal of Chongqing second normal university, 27 (3) (2014) 55-58.

[15] Y. Zou, W. Wang. Study on strategies for improving tourism competitiveness of Zigong City. Journal of Sichuan Tourism Institute, (4) (2015) 74-80.

[16] Y. Liu. Culture is the soul of Tourism: speech at Boao International Tourism Forum 2010. Guangming Daily, 2010 (1)-3-24. 